Aletria, Belo Horizonte, v. 30, n. 1, p. 205-227, 2020

(c) (1)

\title{
Borges: índoles da nacionalidade, problemas do nacionalismo
}

\section{Borges: Characteristics of Nationality, Nationalism Problems}

\author{
Newton de Castro Pontes \\ Universidade Regional do Cariri (URCA), Crato, Ceará / Brasil \\ newtondecastrop@hotmail.com \\ http://orcid.org/0000-0002-9960-0019
}

Resumo: A fim de compreender como a discussão sobre nacionalidade literária se expressou na produção de Jorge Luis Borges, este artigo analisa três diferentes ensaios escritos pelo autor argentino entre os anos 1920 e 1950 - "Queja de todo criollo" (1926), "Nuestro pobre individualismo" (1946) e "El escritor argentino y la tradición" (1953) -, nos quais são discutidos problemas relacionados ao nacionalismo na literatura argentina, especialmente questões sobre o criollismo, a poesia gauchesca (no que se destaca o épico Martín Fierro, de José Hernández) e as relações entre o escritor latino-americano e a tradição literária europeia. Para melhor entender a posição de Borges, recorremos também aos estudos de Antonio Candido ("Literatura e subdesenvolvimento") e de Silviano Santiago ("O entre-lugar do discurso latino-americano") sobre os problemas da imitação e da assimilação nas literaturas latino-americanas; por fim, apontamos em Machado de Assis, elementos precursores das discussões de Borges, tal como foram percebidos por Leyla Perrone-Moisés em "Machado de Assis e Borges: nacionalismo e cor local".

Palavras-chave: Jorge Luis Borges; nacionalismo literário; poesia gauchesca; criollismo; literatura argentina; literatura latino-americana.

Abstract: In order to understand how the discussion on literary nationality expressed in Jorge Luis Borges' literary works, we analyse three different essays. They were written by the Argentine author between the 1920s-50s - "Queja de todo criollo" (1926), "Nuestro pobre individualismo" (1946) and "El escritor argentino y la tradición" (1953) - in which he debates problems related to nationalist views in Argentine literature, especially issues about criollismo, gauchesca poetry (with an emphasis on Martín Fierro, José Hernández's epic) and the relations between Latin American writers and the 
European literary tradition. To better comprehend Borges' position on the subject, we refer to the studies written by Antonio Candido ("Literatura e subdesenvolvimento") and Silviano Santiago ("O entre-lugar do discurso latino-americano") about the problems of imitation and assimilation in Latin American literatures. Lastly, we find in Machado de Assis precursory elements of Borges' discussions, as those were pointed out by Leyla Perrone-Moisés in "Machado de Assis e Borges: nacionalismo e cor local".

Keywords: Jorge Luis Borges; literary nationalism; gauchesca poetry; criollismo; Argentine literature; Latin American literature.

\section{Introdução}

A vasta erudição de Jorge Luis Borges, expressa sem reservas tanto na ficção quanto na crítica literária, sempre impôs uma série de problemas aos que se dedicam a estudar sua obra. O desafio mais óbvio está em seu caráter cosmopolita: ao evitar uma expressão superficialmente localista, cada um dos contos, poemas, roteiros e ensaios de Borges dialogam com um grande número de tradições literárias, as quais se espraiam no tempo e no espaço. Seu primeiro livro de contos, Historia universal de la infamia, de 1935, representa bem esse diálogo ao apresentar suas ficções como traduções de trechos das Mil e uma noites, da Enciclopédia britânica e de diversas obras sobre a China, o Japão, a Pérsia e os Estados Unidos (algumas dessas obras complementadas por outras, inventadas pelo próprio Borges). Entre os ensaios, pode-se mencionar Textos cautivos, livro que reúne discussões escritas entre 1936-1939 e nas quais Borges já abordava desde literatura medieval japonesa, ao escrever sobre Genji Monogatari, até obras que lhe eram contemporâneas, provenientes de diversos países e línguas.

Um segundo desafio aparece então por antítese: se a obra de Borges tende ao cosmopolitismo, descobrir nela o que há de nacional ou regional revela outro conjunto de dificuldades. Claro que, antes de identificar supostos traços de nacionalidade na obra de Borges, há outra questão muito mais imediata, sobre a qual pretendemos nos debruçar aqui: a de como Borges compreendia a própria ideia de nacionalidade literária. Para um escritor latino-americano no século XX, o problema da representação literária do nacional torna-se ainda mais decisivo, e foi algo que de fato afetou diretamente as primeiras recepções de Borges na Argentina. Podemos encontrar um levantamento dessa primeira fortuna crítica e uma discussão sobre ela em $O$ fingidor e o censor, de Luiz Costa 
Lima: este aponta como o problema do nacional foi levantado, já em 1930, por Nestor Ibarra, que falava em características de Borges que o distanciavam irrevocavelmente da pátria e que o considerava fabricante de uma pátria que lhe bastava. Embora Ibarra não desdenhasse da obra de Borges, de quem foi um apreciador, esse comentário crítico logo adquiriria um tom agressivo em outros resenhistas; afinal, como apontou Lima (1988, p. 259), "numa América Latina, em que a tradição documentalista era a variante mais prestigiosa do essencialismo (a argentinidade, a mexicanidade, etc.), questionar o espírito nacional de um escritor equivalia a um ato acusatório". O mesmo problema reaparece, então, nas críticas de Anderson Imbert, que acusava Borges de não ser nem remotamente um crítico ou pensador nacional; de R. Doll, para quem a produção de Borges era antiargentina por sua carência de tom afetivo, e, posteriormente, de H. A. Murena, para quem Borges reduzia ou empobrecia as formas da realidade presente em favor do passado e por isso se negava a possibilidade de experimentar o sentimento nacional (LIMA, 1988, p. 259-260).

As impressões daquela parte não pouco significativa da crítica argentina, ávida por uma literatura localista de caráter documental e essencialista, não foram ignoradas por Borges. Dentre os vários ensaios em que se pode dizer que o problema da representação nacional foi de algum modo discutido pelo escritor, pelo menos três se sobressaem pela centralidade do tema; também ajuda o fato de terem sido escritos em períodos distintos, o que nos permite avaliar o desenvolvimento de um raciocínio ao longo de mais de vinte anos: "Queja de todo criollo" [Queixa de todo criollo] foi publicado em 1926 em Inquisiciones; "Nuestro pobre individualismo" [Nosso pobre individualismo] foi escrito em 1946 e reunido com mais ensaios em Otras inquisiciones, de 1952; por fim, "El escritor argentino y la tradición" [O escritor argentino e a tradição] corresponde a uma aula enunciada originalmente em 1951 e publicada na revista Cursos y conferencias em 1953, tendo sido finalmente incluída na segunda edição do livro Discusión em 1957.

\section{Aparência e essência nacionais: o criollismo}

A seguinte passagem encontra-se já no início do mais antigo deles - "Queja de todo criollo" - e prenuncia as críticas que seriam dirigidas a Borges nos anos 1930 (mas cujas tendências já estavam em pleno vigor quando o ensaio foi escrito): 
Mostram as nações duas índoles: uma obrigatória, de convenção, feita de acordo com os requerimentos do século e, na maioria das vezes, com o prejuízo de algum definidor famoso; outra verdadeira, entranhável, que a pausada história vai declarando e que transparece também pela linguagem e os costumes. Entre ambas as índoles, a aparencial e a essencial, costuma-se advertir uma contrariedade notória. ${ }^{1}$ (BORGES, 2012, p. 121, tradução nossa).

A distinção, que foi retomada em textos posteriores, merece ser enfatizada: a índole aparencial de uma nação é convencional, obrigatória (portanto, imposta) e momentânea, obedecendo a "requerimentos do século"; já a índole essencial é verdadeira e entranhável, mostrando-se ao longo da história, na linguagem e nos costumes. Vê-se nesse e em outros ensaios que a aparência e a essência do nacional não são características complementares, mas antitéticas, e a exaltação de uma delas se dá em detrimento da outra.

Como isso se manifesta no caso das nações hispano-americanas? Borges pensa na figura do criollo, ${ }^{2}$ o descendente de espanhóis (ou, mais

\footnotetext{
1 "Muestran las naciones dos índoles: una la obligatoria, de convención, hecha de acuerdo con los requerimientos del siglo y las más veces con el prejuicio de algún definidor famoso; otra la verdadera, entrañable, que la pausada historia va declarando y que se trasluce también por el lenguaje y las costumbres. Entre ambas índoles, la aparencial y la esencial, suele advertirse una contrariedad notoria."

${ }^{2}$ Segundo a descrição do termo "Criollo" em A Dictionary of Borges, de Evelyn Fishburn \& Psiche Hughes (1990, p. 65; tradução nossa), "Do português crioulo, "criança de peito', um termo originalmente aplicado a 'brancos' nascidos de ascendência europeia. Com a crescente miscigenação, porém, passou a ser dado a nativos de sangue misto. A palavra tem várias aplicações, desde a elite local de alto escalão, aos líderes do Movimento de Independência, até as massas de mestiços, normalmente com conotações pejorativas. Como observa R. B. Scobie, 'No século XIX, criollo se tornou sinônimo de malandragem e preguiça' (Buenos Aires from Plaza to Suburb, Oxford 1974, p. 219)". ["From the Portuguese crioulo, 'nursling', a term. originally applied to 'whites' born of European parentage. With increasing miscegenation, however, it was given to natives of mixed blood. The word has wide applications, from the high-ranking local élite, the leaders of the Independence Movement, to the native mestizo masses, often with pejorative connotations. As R.B. Scobie observes, 'In the nineteenth century, criollo became synonymous with shiftiness and laziness' (Buenos Aires from Plaza to Suburb, Oxford 1974, 219)".]
} 
geralmente, de europeus) nascido na América e que busca construir uma identidade própria. Uma das marcas centrais de tal identidade seria o desengano, que Borges exemplifica brevemente por meio de figuras e eventos históricos - Rosas, Irigoyen, Don Juan Manuel, San Martín e Quiroga. No entanto, nesse ensaio, a ideia de criollismo se desenvolve, não por um exame das relações histórico-sociais, mas por suas manifestações literárias, especificamente da lírica criolla: o que, claro, está de acordo com a proposta inicial de que a índole essencial de uma nação transparece por meio de sua linguagem. O criollo deve ser considerado menos como um descendente da Espanha e mais um descendente da literatura espanhola; tanto é que Borges utiliza a certa altura, o Dom Quixote e a Epistola moral na construção de seu argumento. Segundo ele, o criollo seria marcado por um tipo de sorridente fatalismo encontrado naquelas duas obras (as melhores da literatura espanhola, na opinião de Borges), as quais seriam exaltações do fracasso: daí que os motivos centrais na lírica popular criolla seriam "O sofrimento, as saudades brandas, a burla maliciosa e sossegada"3 (BORGES, 2012, p. 123, tradução nossa), e nela não haveria assombro de metáforas.

O criollismo se torna, em outros termos, um problema de estrutura literária, a qual pode ser descoberta, principalmente, em versos gauchescos: tornam-se material para o comentário de Borges, os versos de Estanislao del Campo, algumas estrofes do épico Martín Fierro, de José Hernández, um dístico anônimo e o Leopoldo Lugones de El solterón e de Quimera lunar. De modo geral, Borges (2012, p. 122, tradução nossa) considera que o criollo é "zombador, suspeito, desenganado de antemão de tudo e tão mal sofredor da grandiosidade verbal que em pouquíssimos a perdoa e em ninguém a exalta"; ${ }^{4}$ no que diz respeito ao seu modo poético de sentir e representar a realidade, "A tristeza, a burla imóvel, a insinuação irônica, eis aqui os únicos sentires que uma arte criolla pode pronunciar sem sair forasteira"s (BORGES, 2012, p. 125, tradução nossa). Em relação ao cômico, enquanto a poesia andaluz alcança "o jocoso mediante o puro disparate e a hipérbole, o criollo o

\footnotetext{
3 "El sufrimiento, las blandas añoranzas, la burla maliciosa y sosegada [...]."

4 “[...] burlón, suspicaz, desengañado de antemano de todo y tan mal sufridor de la grandiosidad verbal que en poquísimos la perdona y en ninguno la ensalza." 5 "La tristura, la inmóvil burlería, la insinuación irónica, he aquí los únicos sentires que un arte criollo puede pronunciar sin dejo forastero."
} 
solicita, fragmentando uma expectativa, prometendo ao ouvinte uma continuidade que infringe de golpe"6(BORGES, 2012, p. 194, tradução nossa). Tudo isso diz respeito ao essencial. Quanto ao que representaria a índole aparencial, Borges menciona em termos nada elogiosos os "gritadores" como Ricardo Rojas, feitos de espuma, patriotismo e um insondável nada, "um vexame paradoxal de nossa verdadeira forma de ser"’ (BORGES, 2012, p. 125, tradução nossa) - autores que, segundo ele, teriam muito mais de grandioso que de legível.

Por outro lado, um caso profundamente complexo e curioso se encontra na figura de Lugones. Parte de sua obra é tratada como uma expressão da essência do criollismo (principalmente a poesia), mas outra parte (especialmente os contos) é vista como herdeira do gongorismo e de escritores como Herrera y Reissig, Laforgue e Goethe - isto é, de expressões do sentimento romântico e simbolista e de um manejo barroco da linguagem. Nada disso é considerado, entretanto, em detrimento de Lugones: exceto pela consideração de que os contos de horror seriam bocejantes (posição revista por Borges nos anos 1950, ao escrever Leopoldo Lugones), a sua obra como um todo é tratada, inclusive, como superior à de Fernández Moreno, esta sim uma manifestação criolla. Aquela parcela da obra de Lugones, tão afastada do criollismo, expressaria, na verdade, a forma de uma dilemática tragédia com a qual se identificariam os argentinos (ou pelo menos os escritores argentinos) do século XX: a do criollo que tenta descriollar-se como maneira de derrotar as forças de seu tempo - possivelmente as mesmas que constituíam o nacionalismo.

Ou seja: observar a contrariedade entre as duas índoles não significa dizer que a literatura deve necessariamente expressar a essência da nação; no caso de Lugones, a própria rejeição de uma suposta identidade regional torna-se o elemento de identificação que revela o triunfo de sua obra. Infelizmente, a produtiva leitura que Borges propunha de Lugones nem sempre foi seguida pela crítica - e, assim, não deixa de ser um desalento que, já nos anos 1950, críticos como Adolfo Prieto aproximassem as obras de Borges e Lugones e as criticassem como um

\footnotetext{
6 “[...] la jocosería mediante el puro disparate y la hipérbole, el criollo la recaba, desquebrajando una expectación, prometiendo al oyente una continuidad que infringe de golpe."

7 “[...] un vejamen paradójico de nuestra verdadera forma de ser."
} 
deslumbramento do vazio, o que foi seguido pelas leituras estritas de J. C. Portantiero e J. J. Hernández, as quais consideravam a ausência de uma imagem do homem (na verdade, a ausência de uma representação essencialista, aparencial da realidade latino-americana) como traços de uma cultura superficial, ligada à elite colonial e preocupada em divulgar literaturas estrangeiras (LIMA, 1988, p. 261-262).

Tendo em vista a agressividade com que tal tradição crítica se voltou contra as ideias bem mais profundas de nacionalidade que Borges buscava construir em sua obra, não é acidente que as palavras argentinidade e progresso apareçam, em seu ensaio, como vocábulos de significado hostil e que ele rejeite a reverência exacerbada concedida a elas, enquanto as considera parcialmente responsáveis pelo sentimento de que o criollo se perdia enquanto a pátria se tornava altiva e insolente - a essência verdadeira, de longa construção histórica e existente na linguagem e costumes, dava lugar à predileção pela aparência, convencional, momentânea e imposta como obrigação.

No que pese a rejeição às ideias de argentinidade e de um nacionalismo aparencial, o primeiro dos três ensaios possui um direcionamento claramente diferente dos demais: há nele um tom ainda prescritivo, que o situa entre um ensaio e um manifesto. Longe de rejeitar a preocupação nacionalista, procura antes corrigi-la, propondo o que seria uma nacionalidade verdadeira - nacionalidade que, deve-se observar, é herdada da literatura espanhola e mesclada a um sentimento local. Com todas as concessões que devem ser feitas ao modo como Borges já apontava problemas no nacionalismo e pensava no nacional como uma questão de estrutura literária e de um modo de sentir o mundo (e não apenas de conteúdo, de uma cor local), seu pensamento ainda remete às preocupações que encontramos em escritores latino-americanos durante a formação das literaturas nacionais no século XIX. No caso do Brasil, pode-se apontar como exemplo comparativo aquilo que José de Alencar escreveu em "Bênção paterna", prefácio para Sonhos d'ouro:

Aos que tomam ao sério estas futilidades de patriotismo, e professam a nacionalidade como uma religião, a esses hás de murmurar baixinho ao ouvido, que te não escutem praguentos, estas reflexões:

"A literatura nacional que outra cousa é senão a alma da pátria, que transmigrou para este solo virgem com uma raça ilustre, aqui impregnou-se da seiva americana desta terra 
que the serviu de regaço; e cada dia se enriquece ao contato de outros povos e ao influxo da civilização?" (ALENCAR, 1959, p. 697)

Com isso não se deve pensar que os dois escritores tenham concepções semelhantes ou que suas conclusões atinjam alguma convergência; apontamos apenas que a tentativa de uma caracterização do nacional, a recusa aos que professam a "nacionalidade como religião" e a literatura americana pensada a partir da migração europeia já estavam entre as preocupações românticas. Fora isso, Borges pensa a cultura criolla como algo autônomo, e sua lírica, embora se identifique com expressões da literatura espanhola (o Dom Quixote e a Epístola moral), toma um caráter inteiramente próprio - a relação do criollismo com a Espanha é uma relação transformadora; já Alencar, reduz as nações nativas brasileiras a um povo primitivo que "recebia [dos portugueses] a cultura" (ALENCAR, 1959, p. 697) e que sua gestação lenta "devia sair da estirpe lusa, para continuar no novo mundo as gloriosas tradições de seu progenitor" (ALENCAR, 1959, p. 697). Além disso, a virilidade de uma nação, para Alencar, consistia em "um eu próprio, que resiste ao prurido da imitação" (1959, p. 698), caso europeu, enquanto os povos americanos seriam "povos não feitos; estes tendem como a criança ao arremedo; copiam tudo, aceitam o bom e o mau, o belo e o ridículo, para formarem o amálgama indigesto, limo de que deve sair mais tarde uma individualidade robusta" (ALENCAR, 1959, p. 698). É evidente que para Borges, a influência de outros povos e suas literaturas nunca foi um problema (não seria apenas um traço defeituoso de um povo ainda por se fazer), e mesmo o conceito de imitação em sua obra adquiriu um caráter inteiramente novo e positivo, conforme discutiremos posteriormente.

Voltando ao texto de Borges, nele a poesia gauchesca aparece, sem uma crítica aprofundada nesse aspecto, como expressão do criollismo; vinte e cinco anos depois, Borges passaria a diferenciar a poesia gauchesca da poesia dos gaúchos, discutindo o convencionalismo de obras como o Martín Fierro - sem prejuízo à sua qualidade, mas observando o aspecto artificial por trás do que define literariamente o gaúcho e seu mundo no épico de José Hernández e em outras poesias semelhantes. 


\section{Pátria e individualismo}

De qualquer modo, um pouco antes disso, em 1946, encontramos um debate que, apesar de breve, é ainda mais contundente acerca do problema da pátria. O ensaio "Nuestro pobre individualismo" foi escrito em 1946, ano em que Juan Domingo Perón assumiu a presidência da Argentina, fato que não é acidental para o tom em que o texto está escrito: Borges foi um famoso opositor político do peronismo e crítico de qualquer tendência política que ampliasse o campo de atuação do governo, exprimindo claramente sua preferência por um estado mínimo. Suas críticas severas ao fascismo e o nazismo, mesmo em um período em que certos setores da intelectualidade argentina (incluindo escritores como Lugones) ainda demonstravam uma inclinação aos ideais de nação expressos por aquelas ideologias totalitárias, também se estenderam ao comunismo, no qual via uma antítese da individualidade; o nacionalismo peronista, ainda que se propusesse a superar tanto o capitalismo quanto o comunismo, tampouco lhe agradou. No ensaio de 1946, Borges escreve que:

O mais urgente dos problemas de nossa época (já denunciado com profética lucidez pelo quase esquecido Spencer) é a gradual intromissão do Estado nos atos do indivíduo; na luta contra esse mal, cujos nomes são comunismo e nazismo, o individualismo argentino, acaso inútil ou prejudicial até agora, encontrará justificação e deveres. ${ }^{8}$ (BORGES, 2012, 195, tradução nossa)

Assim, sua percepção da política argentina naquele momento certamente foi decisiva para que se reacendesse em sua crítica o sentido negativo de termos como patriotismo, nacionalismo e Estado, os quais aparecem em oposição a indivíduo.

Se no primeiro ensaio Borges ponderara que o desengano é a marca central do criollo, neste ele pensa que uma das grandes diferenças entre os europeus e americanos do norte e os argentinos é que estes não se identificam com o Estado - eles são indivíduos, e não cidadãos. A

\footnotetext{
8 "El más urgente de los problemas de nuestra época (ya denunciado con profética lucidez por el casi olvidado Spencer) es la gradual intromisión del Estado en los actos del individuo; en la lucha con ese mal, cuyos nombres son comunismo y nazismo, el individualismo argentino, acaso inútil o perjudicial hasta ahora, encontrará justificación y deberes."
} 
isso, atribui duas causas: 1) os governos na Argentina costumam ser péssimos; 2) os argentinos só concebem relações pessoais, mas o Estado é impessoal.

Ainda que o assunto tenha se modificado do criollo para o argentino de modo geral, e do desengano/sorridente fatalismo para a individualidade, o que permanece constante nos dois ensaios é o recurso à literatura e o reconhecimento de algum traço essencial da nacionalidade argentina no Dom Quixote - a descendência literária é novamente ressaltada aqui. Dessa vez, Borges parte de algo dito por dom Quixote no volume I, capítulo XXII do romance de Cervantes: "De pecados particulares, cada um lá se avenha. Lá em cima está Deus, que não se descuida de castigar aos maus e premiar aos bons, e não é bem que os homens honrados se tornem verdugos dos seus semelhantes, não tendo que meter aí a pata" (CERVANTES, 1963, p. 192). A escolha não é acidental: trata-se do momento em que dom Quixote liberta um grupo de prisioneiros que era levado pela guarda. Segundo Borges, há uma afinidade íntima de tal situação com aquela que se encontra em Martín Fierro, no Canto IX, quando o sargento Cruz se revolta contra seus próprios soldados ao notar a injustiça dos ataques da polícia contra o solitário e valente Martín Fierro, a quem acode (HERNÁNDEZ, [199-?], p. 46). Nos dois casos há a revolta contra a injustiça da ação de uma força do Estado contra o indivíduo. Borges também aponta que enquanto no cinema de Hollywood o herói pode se tornar amigo do criminoso para entregá-lo à polícia, na Argentina tal ato seria visto como uma canalhice - pois a polícia é vista como uma máfia, e a amizade é uma paixão. Trata-se de uma reafirmação da relação pessoal (amizade) sobre a impessoal (dever com a polícia), e do indivíduo sobre o Estado - de modo geral, essa é a caracterização que recebe a nacionalidade argentina no ensaio de 1946.

\section{A posição dos escritores argentinos e sul-americanos na cultura ocidental}

Já nos anos 1950, em “El escritor argentino y la tradición”, Borges tentava aprofundar sua discussão por meio de algumas considerações sobre o Martín Fierro e a poesia gauchesca. Dos três ensaios, esse é o mais conhecido: no Brasil, foi objeto de estudo no revelador artigo de Leyla Perrone-Moisés, "Machado de Assis e Borges: nacionalismo e cor local", o qual encontra em Borges uma visão sobre a cor local que 
o aproxima de Machado de Assis e vê em ambos uma recusa a reduzir a literatura às expressões do nacionalismo.

Partindo de afirmações de Lugones e de Ricardo Rojas, Borges recorda a centralidade do Martín Fierro na épica argentina. Para aqueles autores, a obra de José Hernández deveria ser para os argentinos o que os poemas épicos foram para os gregos; aquele épico, reconhecido como uma poesia gauchesca, deveria ser visto como o arquétipo de toda a tradição literária argentina (que, então, seria extensão da poesia gauchesca, expressão natural e verdadeira da nação).

Já percebemos a inclinação de Borges para diferenciar aparência de essência, o que aqui se repete por meio de uma questão inicial: a de que há uma larga diferença entre a poesia dos gaúchos (de seus payadores, poetas populares) e a poesia gauchesca - isto é, entre a poesia popular e a poesia letrada que deliberadamente busca reproduzir suas formas. Há uma ênfase de Borges sobre o uso da linguagem, a partir do qual conclui que a poesia dos payadores é tratada, em sua enunciação, como algo importante, que busca, instintivamente em sua expressão, evitar as vozes populares e procura os efeitos altissonantes. Conclui também que os payadores evitam o "versificar em orillero ou lunfardo e tratam de expressar-se com correção"9 (BORGES, 1997, p. 193, tradução nossa), e, embora fracassem no uso do espanhol formal, tal acontece acidentalmente, pois o seu propósito é a poesia elevada - "distinguida", como diria Borges. Consequentemente, ela tampouco está preocupada em manifestar qualquer cor local: o payador fala de temas gerais, inclusive abstratos; seus conteúdos não são particularmente gaúchos.

A poesia gauchesca, por outro lado, tem a intenção de criar uma voz popular, de apresentar-se como se fosse dita por gaúchos (BORGES, 1997, p. 191) - o que, paradoxalmente, diferencia-a daquilo que tenta mimetizar, preenchendo sua lírica de elementos da vida pastoril e evidenciando uma preocupação com a cor local que, na poesia dos gaúchos, está completamente ausente. Isso tudo faria da poesia gauchesca um gênero pleno de convenções e tão artificial quanto qualquer outro.

O conceito de cor local sempre teve uma centralidade desmedida nas literaturas latino-americanas. Mencionamos anteriormente um prefácio de Alencar (1959, p. 698) em que o termo aparece associado à ideia de uma pureza original, "sem mescla", e às tradições, costumes e

9 “[...] versificar en orillero o lunfardo y tratan de expresarse con corrección.” 
linguagem do passado singelo de um povo em que a "luz da civilização" ainda não se propagou - é seguro afirmar que tal concepção, salvo algumas exceções, dominou as discussões literárias latino-americanas em seu período fundador, nos romantismos do século XIX. Já vimos, no ensaio anterior de Borges, que o criollismo fora concebido desde o princípio, a partir de uma relação de descendência transformadora com a fonte espanhola, de modo que a ideia de uma pureza original lhe seria totalmente estranha - e pensava nos costumes e na linguagem como propiciadores de uma forma de sentir o mundo, e não como elementos que deveriam aparecer diretamente nas obras literárias. Vinte e cinco anos depois, sua posição se tornou ainda mais enfática, assumindo que "o verdadeiramente nativo pode e costuma prescindir de cor local"10 (BORGES, 1997, p. 195, tradução nossa). De fato, a sua discussão sobre Maomé e o Alcorão busca demonstrar justamente como a visão de mundo de um povo pode se expressar e ser identificada pela ausência de um elemento tradicionalmente visto como definidor da cor local: mais precisamente, Borges nota que a autenticidade do Alcorão está demonstrada pela ausência de camelos no livro. Isso porque, para um escritor estrangeiro, a quem interessam os elementos que marcam a cultura árabe e a diferenciam da sua, o camelo salta aos olhos como elemento de destaque; para um árabe, é só um animal como qualquer outro, parte da realidade (e não daquela cultura em particular):

Foi escrito por Maomé, e Maomé, como árabe, não tinha por que saber que os camelos eram especialmente árabes; eram para ele parte da realidade, não tinha por que os distinguir; por outro lado, um falsário, um turista, um nacionalista árabe, a primeira coisa que teria feito seria prodigar camelos, caravanas de camelos em cada página; porém Maomé, como árabe, estava tranquilo: sabia que podia ser árabe sem camelos. Creio que nós argentinos podemos nos parecer com Maomé, podemos crer na possibilidade de ser argentinos sem abundar na cor local. ${ }^{11}$ (BORGES, 1997, p. 195-196, tradução nossa).

\footnotetext{
10 “[...] lo verdaderamente nativo suele y puede prescindir de color local."

11 "Fue escrito por Mahoma, y Mahoma, como árabe, no tenía por qué saber que los camellos eran especialmente árabes; eran para él parte de la realidad, no tenía por qué distinguirlos; en cambio, un falsario, un turista, un nacionalista árabe, lo primero que hubiera hecho es prodigar camellos, caravanas de camellos en cada página; pero
} 
A cuidadosa observação demonstra que expressão de nacionalidade e cor local podem ser mutuamente excludentes, ao contrário do que pregavam os nacionalistas; que a ênfase sobre a particularidade local pode, paradoxalmente, denunciar a falta de familiaridade entre um autor e o povo que tenta representar, ou, mais exatamente, a visão de mundo desse povo. Mas o problema do nacionalismo na literatura vai além disso: pois a própria ideia de que a nação de um autor deve servir de fonte para seus temas literários seria completamente estranha aos escritores clássicos, celebrados pelo cânone ocidental. Se as literaturas latino-americanas estavam preocupadas em equiparar-se à tradição europeia que lhes servia de modelo, como explicar sua ênfase na cor local se esta é completamente ausente em, digamos, Racine ou Shakespeare? Borges menciona os dois dramaturgos justamente para apontar o fato de que Racine está entre os grandes nomes da literatura francesa e, no entanto, suas tragédias não se passam na França; Shakespeare, igualmente, definiu a literatura inglesa enquanto representava personagens e temas da Dinamarca, da Itália, da Escócia e de outros lugares.

A obrigação da expressão nacional, especialmente por meio dos regionalismos que exigem a cor local como traço pitoresco, deve ser vista como um problema mais profundo dentro das relações entre os países colonizados e a Europa. Antonio Candido, por exemplo, percebeu nisso um problema artístico ligado ao subdesenvolvimento e à dependência dos países latino-americanos - em "Literatura e subdesenvolvimento", a questão é apresentada da seguinte maneira:

Considerada como derivação do atraso e da falta de desenvolvimento econômico, a dependência tem outros aspectos que manifestam a sua repercussão na literatura. Lembremos de novo o fenômeno da ambivalência, traduzida por impulsos de cópia e rejeição, aparentemente contraditórios quando vistos em si, mas que podem ser complementares se forem encarados desse ângulo.

Atraso que estimula a cópia servil de tudo quanto a moda dos países adiantados oferece, além de seduzir os escritores com a migração, por vezes migração interior,

Mahoma, como árabe, estaba tranquilo: sabía que podía ser árabe sin camellos. Creo que los argentinos podemos parecernos a Mahoma, podemos creer en la posibilidad de ser argentinos sin abundar en color local." 
que encurrala o indivíduo no silêncio e no isolamento. Atraso que, entretanto, no outro lado da medalha, propõe o que há de mais peculiar na realidade local, insinuando um regionalismo que, ao parecer afirmação da identidade nacional, pode ser na verdade um modo insuspeitado de oferecer à sensibilidade europeia o exotismo que ela desejava, como desfastio; e que se torna desta maneira forma aguda de dependência na independência. Com a perspectiva atual, parece que as duas tendências são solidárias e nascem da mesma situação de retardo ou subdesenvolvimento. (CANDIDO, 2006, p. 189).

A ênfase na cor local aparece como uma forma do exotismo, suprindo mais um desejo turístico do colonizador que uma afirmação do colonizado, e sua motivação é a própria dependência econômica e cultural - questão que Borges também expressou em seu ensaio ao notar que, ironicamente, "O culto da cor local é um recente culto europeu que os nacionalistas deveriam rejeitar como estrangeiro"12 (1997, p. 195, tradução nossa). Um dos problemas que Candido encontra na evolução das literaturas latino-americanas é o seu vínculo placentário com as europeias: aquelas se desenvolvem como ramos destas, o que sempre provocou um problema fundamental no debate sobre a originalidade artística dos quadros e técnicas expressivas nos países colonizados. Por trás de toda a exigência no uso de temas, costumes e linguagens locais (desde que se limitassem à demonstração da aclimatação dos idiomas europeus nas terras americanas), as literaturas latino-americanas não se furtaram a importar, sem restrições, os gêneros, as tendências e as técnicas de escrita europeias - a cor local, exigida no plano dos conteúdos, nunca levou a uma contestação das formas, de modo que a originalidade se limitou à inserção do traço exótico em modelos artísticos europeus.

Antonio Candido supõe, além disso, que a superação da dependência passa não pela afirmação localista do nacional ou pelo regionalismo pitoresco (que, ao contrário, reforçam a condição de colônia), mas sim pela capacidade de produzir "obras de primeira ordem, influenciadas, não por modelos estrangeiros imediatos, mas por exemplos nacionais anteriores" (CANDIDO, 2006, p. 184) - o que significa a

12 "El culto argentino del color local es un reciente culto europeo que los nacionalistas deberían rechazar por foráneo." 
criação de uma causalidade interna no sistema literário de um povo, a qual tornaria, inclusive, as influências de outras culturas mais fecundas (pois elas passariam a ser reformuladas nos termos de um sistema com desenvolvimento próprio, e não mais como padrões de imitação). Por fim, a superação da dependência cultural aponta a possibilidade de que a arte dos países colonizados influa sobre as metrópoles - curiosamente, Borges é considerado justamente como "o primeiro caso de incontestável influência original, exercida de maneira ampla e reconhecida sobre os países-fontes através de um modo novo de conceber a escrita" (CANDIDO, 2006, p. 185).

Retome-se, ainda, a segunda tendência apontada por Candido: se, por um lado, a ênfase na cor local é uma das faces da ambivalência entre cópia e rejeição, a outra face complementar se trata da cópia servil. Borges também se refere a isso em seu ensaio: a segunda solução discutida para o problema da tradição é aquela que apresenta a tradição espanhola como única a que os argentinos deveriam recorrer (pense-se em como Alencar concebia os brasileiros como um povo em gestação que deveria continuar no novo mundo as gloriosas tradições de seus progenitores portugueses...). Sua recusa a tal proposição se dá por dois motivos: por um lado, considera que, entre os argentinos, o gosto pela literatura espanhola não é natural, mas adquirido, e de fato sua aquisição é mais difícil que o de outras literaturas, sendo menos uma capacidade herdada e mais uma prova da versatilidade argentina; por outro lado, assume que a história argentina pode definir-se, "sem equívoco, como um querer apartar-se da Espanha, como um voluntário distanciamento da Espanha"13 (BORGES, 1997, p. 198, tradução nossa).

O raciocínio é reminiscente daquilo que se dizia, em "Queja de todo criollo", a respeito de Leopoldo Lugones, do problema do criollo que tenta se descriollar. Aquela dilemática tragédia passa a se reproduzir, então, nas duas direções: o escritor argentino se recusa a se definir por uma identidade exclusivamente local; recusa-se, também, a se definir em relação à antiga metrópole, seja como continuidade ou extensão dela. Nem servilismo, nem exaltação nacional: é necessário encontrar outra tradição com que se identificar.

13 “[...] sin equivocación como un querer apartarse de España, como un voluntario distanciamento de España.” 
E que tradição seria essa? Para Borges, ela é toda a cultura ocidental - ou, ainda mais, esse patrimônio é o próprio universo. Sua conclusão é que a discussão inteira de nacionalidade se baseia no erro inicial de supor que os projetos literários e as intenções são importantes, enquanto, na verdade, "ser argentino é uma fatalidade e, nesse caso, seremos de qualquer modo, ou ser argentino será uma mera afetação, uma máscara" ${ }^{14}$ (BORGES, 1997, 203, tradução nossa). Borges não deixa de notar, todavia, que os argentinos (e os sul-americanos em geral) estão em uma posição especial em relação à cultura ocidental, que, segundo ele, é uma posição semelhante à dos judeus em relação ao Ocidente ou dos irlandeses em relação à Inglaterra. Tal posição consiste em atuar dentro de uma cultura, mas não estar preso a ela por uma devoção especial: a América do Sul pode manejar os temas europeus com uma irreverência particular, pois tem contato com eles sem o peso dado pelas superstições que o legado da tradição cultural alimenta ao longo de séculos.

\section{Algumas considerações (elementos sucessores em Silviano Santiago; elementos precursores em Machado de Assis)}

Cerca de vinte e cinco anos depois do primeiro ensaio que abordamos aqui, vê-se que a preocupação inicial com a nacionalidade (aparencial ou essencial) abriu espaço para uma reflexão sobre a posição especial do escritor argentino e sul-americano em relação ao todo da cultura ocidental, e mesmo mundial. Daí a importância de que, alguns anos antes, em 1946, Borges expressasse uma oposição tão forte ao nacionalismo e ao Estado, passando a ver o escritor argentino como um indivíduo desconfiado da devoção às grandes entidades impessoais e seus discursos celebratórios, como alguém que não se sente um cidadão de seu Estado - mas sim, pode-se supor, um indivíduo no mundo. Em um momento pioneiro no amadurecimento de um debate sobre as relações entre as culturas pós-coloniais e as antigas metrópoles, algo que se deu a partir dos anos 1950, pela plena consciência de nosso subdesenvolvimento (se tomarmos as observações de Antonio Candido como referência), Borges propôs uma leitura de nossas tradições literárias a partir de uma posição única, que admite abertamente a influência do

14 " $[. .$.$] ser argentino es una fatalidad y en ese caso seremos de cualquier modo, o ser$ argentino es una mera afetación, una máscara." 
modelo e mesmo sua imitação, mas também a capacidade de atuar dentro desse modelo com muito mais liberdade por carregar um comportamento diferente, ingênuo em relação a ele - e, portanto, capaz de transformar o próprio modelo, superando simultaneamente os problemas da cópia servil e do exotismo regionalista.

A conclusão de Borges não permaneceu isolada, e seus ecos podem ser reconhecidos em estudos posteriores sobre a cultura latinoamericana: um dos exemplos mais famosos se trata do ensaio "O entrelugar do discurso latino-americano", escrito por Silviano Santiago e publicado em português no livro Uma literatura nos trópicos, de 1978. A importância da discussão de Santiago está em identificar as razões históricas dos fenômenos da imitação e assimilação nas literaturas latino-americanas, assim como de compreender o papel da tradução, da leitura e da transformação do modelo inspirador na atividade de nossos escritores - elementos que não só estão contidos nas discussões de Borges, como também se encontram em toda a sua produção ficcional. Não é por acidente que Santiago cita justamente um conto de Borges ("Pierre Menard, autor do Quixote") como uma metáfora ideal da posição do escritor latino-americano em relação à tradição europeia.

Santiago (2019, p. 11-14) situa a origem do problema de nossa formação cultural naquilo que ele chama de uma ignorância mútua. Esta se configura, por um lado, pela atitude do colonizador diante das civilizações a serem exploradas no Novo Mundo, um contato inicial que se deu nos termos de um ponto de vista dominador (e não de uma vontade cultural de conhecer), marcado pela violência e pela imposição brutal de uma ideologia, e por uma expressão discursiva que subestimava e desumanizava os colonizados através do uso de termos como animal e escravo. Por outro lado, alguns registros de violência cometida pelos índios (baseando-se na experiência de Porto Rico, conforme discutida por Claude Lévi-Strauss em Tristes trópicos) demonstram que, para estes, a mera assimilação passiva dos sermões cristãos não era suficiente, e que tentavam reproduzir a visão de um acontecimento milagroso: os brancos, capturados e assassinados por imersão, eram então vigiados para se verificar se ressuscitariam ou se eram, como tudo, sujeitos à putrefação. No caso brasileiro, a carta de Caminha também chama a atenção por supor uma predisposição dos nativos a serem convertidos e justificá-la por sua aptidão para imitar os gestos dos cristãos na missa - o que, para Santiago, sugere a questão de que eles talvez procurassem chegar ao 
êxtase espiritual pela duplicação dos gestos; que esperassem encontrar o deus cristão ao final dos exercícios espirituais, tal como os índios de Porto Rico o teriam encontrado diante do branco que se mostrasse imortal.

A consequência para o processo de colonização foi ele ter reunido a representação religiosa (principalmente por meio do teatro) à imposição da língua europeia, em uma união do código religioso ao linguístico. Segundo Santiago, "a América transforma-se em cópia, simulacro que se quer mais e mais semelhante ao original, quando sua originalidade não se encontraria na cópia do modelo original, mas em sua origem, apagada completamente pelos conquistadores" (SANTIAGO, 2019, p. 15) - uma civilização construída pelo fenômeno da duplicação, pelo extermínio dos traços originais e esquecimento da origem; uma nova Europa que, contraditoriamente, copia os valores já ultrapassados da metrópole, criando uma máscara de novidade sobre o atraso.

Em compensação, uma nova sociedade é gerida por esse processo: a mestiçagem latino-americana e os discursos que nascem dela desafiam a unidade humana, linguística, religiosa e cultural almejada pela colonização europeia, e permite que o elemento autóctone se misture de maneira sutil ao europeu, abrindo uma via para a descolonização. Escreve Santiago (2019, p. 17-18) que:

A maior contribuição da América Latina para a cultura ocidental vem da destruição sistemática dos conceitos de unidade e de pureza: estes dois conceitos perdem o contorno exato do seu significado, perdem seu peso esmagador, seu sinal de superioridade cultural, à medida que o trabalho de contaminação dos latino-americanos se afirma, se mostra mais e mais eficaz. A América Latina institui seu lugar no mapa da civilização ocidental graças ao movimento de desvio da norma, ativo e destruidor, que transfigura os elementos feitos e imutáveis que os europeus exportavam para o Novo Mundo.

A centralidade da figura do mestiço nesse processo nos ajuda a compreender por que Borges, no primeiro ensaio abordado aqui, buscou uma índole essencial da nação justamente no criollo, transformando-o em um problema literário (portanto, levando a questão do mestiço ao campo da cultura), e por que rejeitava o termo argentinidade e sua vinculação a uma ideia de pureza patriótica. Daí a importância que pesquisadores como Beatriz Sarlo atribuíram à presença constante da palavra orillas 
(margens, limites) e seus diversos sentidos na obra de Borges: pois não só a literatura argentina seria resultado de um processo de mestiçagem cultural e da assimilação ativa e crítica da tradição europeia, como seria necessário compreender que tal processo se dava em um país marginal. Como escreve Sarlo (2001),

Borges inscreve uma literatura no limite, reconhecendo ali uma forma cifrada da Argentina. Superfície indecisa entre a planície e as primeiras casas da cidade, as "orillas" têm as qualidades de um lugar imaginário, cuja topologia urbano-criolla esboça a clássica rua "sem a calçada oposta". A linha limítrofe se amplia nas "orillas" e, ao mesmo tempo, torna-se porosa porque a cenografia das "orillas" está atravessada por terrenos baldios e paredes de taipa com nichos, pela transparência dos portões de ferro e das cercas de plantas, por balaustradas e varandas, por fachadas que retrocedem detrás das figueiras e pátios que abrem o coração do quarteirão até o céu. [...]. Nas "orillas", a cidade está ainda por se fazer. Borges escreve um mito para Buenos Aires que, em sua opinião, andava necessitando deles. Desde uma recordação que quase não é sua, opõe à cidade moderna esta cidade estética sem centro, construída totalmente sobre a matriz de uma margem (SARLO, 2001). ${ }^{15}$

Voltando para Santiago, a geografia latino-americana buscaria tornar-se espaço de uma assimilação agressiva, não silenciosa, o que insere um problema fundamental na crítica tradicional, que reduz a literatura

15 “Borges inscribe una literatura en el límite, reconociendo allí una forma cifrada de la Argentina. Superficie indecisa entre la llanura y las primeras casas de la ciudad, 'las orillas' tienen las cualidades de un lugar imaginario, cuya topología urbano-criolla dibuja la clásica calle 'sin vereda de enfrente'. La línea del límite se ensancha en 'las orillas' y, al mismo tiempo, se hace porosa porque la escenografía de 'las orillas' está horadada por baldíos y tapias con hornacinas, por la transparencia de las verjas de hierro $\mathrm{y}$ de los cercos de plantas, por balaustradas y balcones, por fachadas que retroceden detrás de las higueras y patios que abren el corazón de la manzana hacia el cielo. [...] En 'las orillas', la ciudad está todavía por hacerse. Borges escribe un mito para Buenos Aires que, en su opinión, andaba necesitándolos. Desde un recuerdo que casi no es suyo, opone a la ciudad moderna, esta ciudad estética sin centro, construida totalmente sobre la matriz de un margen." 
ao estudo das fontes e influências - pois estas, no caso latino-americano, não podem ser interpretadas como a origem que permanece pura frente a uma descendência inferior e parasitária, uma vez que a relação entre a descendência e a fonte passa a ser um elemento transformador desta última. Santiago se refere a isso usando uma frase de Paul Valéry, para quem se alimentar dos outros é normal, mas deve-se digeri-los - o leão é feito de carneiro assimilado; ora, uma frase ainda mais expressiva pode ser encontrada no próprio Borges, que escreveu que "o original é infiel à tradução"16 (BORGES, 2012, p. 315, tradução nossa), sugerindo a possibilidade de que a fonte seja julgada e criticada a partir daquilo que se consideraria, normalmente, sua cópia derivada e inferior.

Para Santiago, é preciso aprender a língua da metrópole para combatê-la; em termos literários, isso significa uma atividade de escrita que se baseie na leitura e reescritura da tradição europeia, em uma cultura literária em que a figura do autor seja também um leitor e tradutor que desarticula e rearticula o texto original segundo uma direção ideológica própria. Daí os dois exemplos de Santiago advirem de ficções que lidam com a tradução e a cópia transformadoras: o romance 62 Modelo para armar, de Cortázar, em que uma personagem ouve um pedido em um restaurante francês e o traduz para o espanhol com um novo sentido, que evoca uma revolução - "Je voudrais un château saignant" torna-se "Quisiera un castillo sangriento" (CORTÁZAR, 1995, p. 5) -, e o conto "Pierre Menard, autor do Quixote", de Borges, em que o escritor-leitor busca reproduzir o texto original de Cervantes enquanto sucede, ao mesmo tempo, em começar a produzir algo que seria completamente novo - mas que, enquanto para Cervantes era uma obra espontânea, para Menard se tornava uma tarefa intencional. Segundo Santiago, "Há em Menard, como entre os escritores latino-americanos, a recusa do 'espontâneo' e a aceitação da escritura como um dever lúcido e consciente”. (SANTIAGO, 2019, p. 27)

Que Silviano Santiago conclua sua discussão por meio da análise de "Pierre Menard", ou que Antonio Candido cite Borges como o primeiro caso de influência original sobre os países-fonte, não é coincidência fortuita. Produzidos nos anos 1970, os estudos de Santiago e de Candido demonstram justamente que a compreensão moderna das culturas literárias latino-americanas e suas vicissitudes, tomadas a

16 "El original es infiel a la traducción [...]." 
partir da consciência de nosso subdesenvolvimento e da relação com o todo da cultura ocidental, especialmente com as antigas metrópoles, retomou muitos dos elementos sugeridos por Borges em seus ensaios e ficcionalizados em seus contos.

As reflexões de Borges, pensadas no conjunto das literaturas latino-americanas, possuem, todavia, seus próprios precursores. $\mathrm{O}$ caso possivelmente mais famoso pode ser encontrado em um texto publicado por Machado de Assis em 1873, intitulado "Instinto de nacionalidade". Embora não atinja a mesma profundidade que o escritor argentino alcançou nos anos 1950 (afinal, trata-se de um ensaio breve, escrito oitenta anos antes por um Machado cuja produção literária ainda não havia amadurecido completamente), esse texto não só pressupõe uma visão universalista similar à de Borges, como também assume posições semelhantes em relação à ideia de cor local e às exigências nacionalistas de modo geral, ainda que escrito em outro período, outro país e outra língua.

Tal afinidade entre os dois autores foi examinada por Leyla Perrone-Moisés; ao notar que ambos consideraram que reduzir a literatura nacional aos temas locais (ou tornar os temas locais exclusivos de uma literatura nacional) seria um empobrecimento temático - afinal, Machado de Assis disse, acerca do indianismo, que "compreendendo que não está na vida indiana todo o patrimônio da literatura brasileira, mas apenas um legado, tão brasileiro como universal, não se limitam os nossos escritores a essa só fonte de inspiração" (ASSIS, 2014, p. 6), ela escreve que:

Esse universalismo dos dois escritores não é, em nenhum deles, um desraizamento, uma perda da identidade nacional. Para o primeiro [Machado de Assis], o que liga fatalmente um escritor à sua nação é "certo sentimento íntimo, que o torne homem de seu tempo e de seu país, ainda que trate de assuntos remotos no tempo e no espaço". Note-se o uso feito pelo escritor das palavras "instinto" e "sentimento". O "instinto" da nacionalidade é aquele afã primário e superficial de ser ostensivamente brasileiro, que ele atribui a uma "opinião mal formada ainda" e à falta, no Brasil, de uma crítica literária "ampla" e "elevada". O "sentimento" da nacionalidade, pelo contrário, é a vivência desta como inerente ao indivíduo de determinada terra e que ele não necessita cultivar como escritor. Borges, de modo análogo, considera que "ser argentino es una 
fatalidad y en ese caso lo seremos de cualquier modo, o ser argentino es una mera afectación, una máscara". (PERRONE-MOISÉS, 2001, p. 104).

Assim, reconhece-se nos dois autores uma distinção entre um sentimento inerente, parte da vivência do sujeito em sua cultura, e um desejo consciente de tornar a literatura uma expressão nacional, ao qual Machado chamou de instinto - trata-se do que Borges havia discutido, em seu primeiro ensaio, nos termos de uma índole essencial e outra aparencial. Perrone-Moisés aponta ainda como Machado utiliza exemplos similares aos de Borges (ao se referir a Shakespeare como um poeta essencialmente inglês que não trata de assuntos particularmente ingleses), e como o escritor brasileiro também se incomoda com o conceito de cor local, tratando-lhe como uma funesta ilusão e uma nacionalidade de vocabulário.

Acima de tudo, tanto Borges quanto Machado tentaram superar as tendências, ainda muito vivas, de nossas primeiras reflexões acerca da identidade cultural latino-americana no século XIX, as quais foram predominantemente construídas em uma relação antitética com a Europa - algo perfeitamente simbolizado pelo conflito entre civilização e barbárie presente em Facundo, de Domingo Faustino Sarmiento, uma das obras mais influentes na América Latina do século XIX. Em Borges, tal como previamente intuído pelo texto de Machado, a reflexão caminha para a questão mais complexa da posição do Outro - a Europa, o Ocidente, o mundo - dentro do paradoxal processo de assimilação e mestiçagem cultural, processo que poderia não diminuir, mas engrandecer tanto a nascente literatura latino-americana quanto a sua fonte mais antiga, a europeia.

\section{Referências}

ALENCAR, José de. Benção paterna. In: . Obra completa. Rio de Janeiro: Aguilar, 1959. v. 1, p. 691-701.

ASSIS, Machado de. Notícia da atual literatura brasileira. Instinto de nacionalidade. Disponível em: http://machado.mec.gov.br/obracompleta-lista/item/109-noticia-da-atual-literatura-brasileira-instintode-nacionalidade. Acesso em: 18 set. 2019. 
BORGES, Jorge Luis. El escritor argentino y la tradición. In: Discusión. Madrid: Alianza Editorial, 1997. p. 188-203.

BORGES, Jorge Luis. Inquisiciones / Otras inquisiciones. Buenos Aires: Debolsillo, 2012.

CANDIDO, Antonio. Literatura e subdesenvolvimento. In: A educação pela noite. Rio de Janeiro: Ouro sobre Azul, 2006. p. 169-196.

CERVANTES, Miguel de. Dom Quixote de la Mancha. Tradução de Aquilino Ribeiro. São Paulo: Difusão Europeia do Livro, 1963.

CORTÁZAR, Julio. 62 Modelo para armar. Buenos Aires: Alfaguara, 1995.

FISHBURN, Evelyn; HUGHES, Psiche. Criollo. In: . A Dictionary of Borges. London: Duckworth, 1990. p. 65.

HERNÁNDEZ, José. El gaucho Martín Fierro y La vuelta de Martín Fierro. Buenos Aires: Editorial Betina, [199-?].

LIMA, Luiz Costa. Aproximação de Jorge Luis Borges. In: . $O$ fingidor e o censor: no Ancien Régime, no Iluminismo e hoje. Rio de Janeiro: Forense-Universitária, 1988. p. 257-306.

PERRONE-MOISÉS, Leyla. Machado de Assis e Borges: nacionalismo e cor local. In: SCHWARTZ, Jorge (Org.). Borges no Brasil. São Paulo: Editora UNESP; Imprensa Oficial do Estado, 2001. p. 101-114.

SANTIAGO, Silviano. O entre-lugar do discurso latino-americano. In: . Uma literatura nos trópicos. Recife: Cepe, 2019. p. 9-30.

SARLO, Beatriz. Borges, un escritor en las orillas. Borges Studies Online. Pittsburgh: J. L. Borges Center for Studies \& Documentation, 2001. E-book. Disponível em: https://www.borges.pitt.edu/bsol/bse3. php. Acesso em: 28 dez. 2019.

Recebido em: 22 de setembro de 2019. 